\title{
A Clinico-Bacteriological Study of Diabetic Foot Ulcers in a Tertiary Care Hospital
}

\author{
Prity Narwade $^{1 *}$ and S.L. Nilekar ${ }^{2}$ \\ ${ }^{1}$ Department of Microbiology, Dr.Shankarrao Chavan Government Medical College, \\ Vishnupuri, Nanded, Maharashtra, India \\ ${ }^{2}$ Department of Microbiology, Swami Ramanand Teerth Rural Government Medical College, \\ Ambajogai, Maharashtra, India \\ *Corresponding author
}

\section{A B S T R A C T}

Diabetic foot is one of the most feared complications of diabetes and is the leading cause of hospitalization in diabetic patients. Diabetic patients have a lifetime risk as high as $25 \%$ for developing into foot ulceration. The reasons for the increased incidence of diabetic ulcer involve the interaction of several pathogenic factors like neuropathy, abnormal foot

\section{Keywords}

Diabetic foot ulcer, Polymicrobial, Antibiotic sensitivity, MRSA

Article Info

Accepted:

07 January 2019

Available Online:

10 February 2019 biomechanics and peripheral arterial disease. The study was performed to determine the microbial etiology (aerobic and anaerobic) of diabetic foot ulcer and their susceptibility pattern in a tertiary care hospital. A total number of 120 diabetic patients were studied over a period of two year. Pus and tissue samples were collected for bacteriological study. The specimens were processed in the Microbiology laboratory for Gram stain, aerobic culture, and anaerobic culture. The organisms isolated were identified by standard procedures and antimicrobial susceptibility was done by Kirby-Bauer disc diffusion method. Out of 120 samples, a total of 227 organisms were isolated in the present study, with an average of 1.87 organisms per specimen. Among them, aerobic organisms were $166(73.1 \%)$ and anaerobic organisms were 61 (26.9\%). Out of 166 aerobic organisms isolated, the most common isolates were Pseudomonas aeruginosa 41(24.70\%) followed by Staphylococcus aureus 33(19.88\%). Amongst 61(26.9\%) anaerobes, Peptostreptococcus magnus (27.8\%) was the commonest isolated organism. Aerobes were found to be susceptible mainly to antibiotics like Vancomycin, Imipenem, Piperacillin - Tazobactum while anaerobes were susceptible to Metronidazole. Pseudomonas aeruginosa was predominant isolate in aerobes while Peptostreptococcus magnus was commonest among anaerobe. This study will help the clinician for proper management of ulcer and thus reduces dreaded complication of it.

\section{Introduction}

Diabetes mellitus is a chronic disorder and affects large segments of population and also a major public health problem ${ }^{1}$. The worldwide prevalence of diabetes now exceeds 200 million and is predicted to rise to more than 300 million in the next 20 years. ${ }^{2}$ The incidence of diabetes in India was estimated to be 31.7 million in the year 2000 
and projected to reach 79.4 million in 2030 , according to the World Health Organisation. ${ }^{21}$

Diabetic foot is one of the most feared complications of diabetes and is the leading cause of hospitalization in diabetic patients. Diabetic foot is characterised by several pathological complications such as neuropathy, peripheral vascular disease, foot ulceration and infection with or without osteomyelitis, leading to development of gangrene and even necessitating limb amputation. $^{18}$

Diabetic patients have a lifetime risk as high as $25 \%$ for developing foot ulceration. ${ }^{19}$ The reason for the increased incidence of diabetic ulcer involve the interaction of several pathogenic factors like neuropathy, abnormal foot biomechanics and peripheral arterial disease $^{3}$. Neuropathy plays the central role with disturbances of sensory, motor and autonomic functions leading to ulceration due to trauma or excessive pressure on a deformed foot that lacks protective sensations ${ }^{12}$. Susceptibility to infections increases due to hyperglycemia and poor vascular supply to the foot. Hence diabetic foot infections are the most common reason for hospital admissions in diabetic patients ${ }^{20}$.

The most important characteristic of the diabetic ulcer is that, it is polymicrobial in nature, comprising of both aerobic and anaerobic microorganisms ${ }^{4}$. In superficial wounds, aerobic bacteria are predominant pathogens. Anaerobic organisms are found more frequently in deeper wounds ${ }^{17}$.

The present study was undertaken to assess the role of aerobic and anaerobic bacteria in the causation of diabetic foot ulcer and their antibiotic susceptibility pattern which would assist clinicians in therapy of this dreaded complication of diabetes.

\section{Materials and Methods}

A prospective study was carried out over a period of two year in Department of Microbiology, at a tertiary care hospital. A total of 120 patients with diabetic ulcer, attending the surgical OPD or admitted in surgical wards, were included in the study. These patients were known diabetic or detected to be diabetic by blood glucose estimation at the time of their visit to the hospital.

A detailed history of the patient regarding age and sex, type of diabetes, duration of diabetes, smoking, hypertension, duration of foot ulcer was taken and recorded. The adequacy of peripheral circulation was done by palpating the posterior tibial artery and the dorsalis pedis artery. Foul smell, local rise of temperature, discharge and discolouration of the surrounding area was noted. Foot ulcers in diabetic patients were categorized into six grades (grade 0 - grade 5) based on Meggit Wagner Classification System ${ }^{10}$. The criterion for inclusion was a diabetic patient with foot ulcer of grade 2 or more.

Samples like pus or necrotic tissues (in case of suspected anaerobic wound) were collected. Before that the surface of the ulcer was rinsed with sterile normal saline, superficial exudates was debrided using a sterile instrument ${ }^{3}$.

Pus was collected from the oozing wound or collected from the infective centre of the wound with the help of sterile cotton tipped swab which was moistened with normal saline or aspirated with the help of sterile needle and syringe (In case of abscess) ${ }^{15,3}$. In case of suspected anaerobic condition, necrotic tissue sample was taken with a sterile blade/knife in wedge shape, including base and margin of ulcer and transported in thyoglycollate broth ${ }^{4}$. 
For aerobic culture, specimen was inoculated on MacConkey's agar and blood agar plates and incubated at $37^{\circ} \mathrm{C}$. For anaerobic culture, Specimen was inoculated on Neomycin blood agar, Kanamycin-vancomycin blood agar and Robertson's cooked meat medium. The inoculated plates were incubated immediately in anaerobic gas pack jar at $37^{\circ} \mathrm{C}$ for 48 hours. The organisms isolated were identified by standard procedures ${ }^{6}$.

Antimicrobial susceptibility testing of aerobic and anaerobic isolates was performed by the Kirby Bauer disc diffusion method as recommended by the Clinical and Laboratory Standards Institute (CLSI) ${ }^{11,5}$.

\section{Results and Discussion}

Out of 120 patients, $71(59.1 \%)$ were males and $49(40.8 \%)$ were females with male to female ratio was $1.4: 1$.Most of the patients with diabetic foot were in the age group 51 to $60(34.1 \%)$ years. About $37(30.8 \%)$ patients had diabetes mellitus for 6-10 years. Only one $(0.84 \%)$ case was insulin-dependent diabetes mellitus and the others were non-insulindependent diabetes mellitus (NIDDM) cases, 119 (99.16\%). Forty one $(34.16 \%)$ patients presented with ulcer of 6-8 month duration, followed by $37(30.83 \%)$ patients had ulcer of 3-5 months duration. The commonest clinical findings seen were fever $(56.6 \%)$, followed by neuropathy $(50.8 \%)$, vasculopathy $(48.3 \%)$, crepitation $(37.5 \%)$ and foul smell (34.1\%).Sixty nine $(57.5 \%)$ patients were smokers and fifty eight $(48.4 \%)$ patients were associated with hypertension. Majority of the patients presented with the ulcer of Wagner grade II, 71(59.2\%), followed by grade III, 27 (22.5\%).Eighty four (70\%) patients had poor glycolic control (BSL> $200 \mathrm{mg} / \mathrm{dl}$ ), while $36(30 \%)$ patients had blood sugar level less than or equal to $200 \mathrm{mg} / \mathrm{dl}$ (Table 1).

A total of 227 organisms were isolated in the present study, with an average of 1.87 organisms per specimen. Among them, aerobic organisms isolated were $166(73.1 \%)$ and anaerobic organisms were 61 (26.9\%).Out of 166 aerobic organisms isolated, the most common isolates were Pseudomonas aeruginosa 41(24.70\%) followed by Staphylococcus aureus 33(19.88\%), Escherichia coli 30(18.08\%), Klebsiella pneumoniae 21(12.65\%), and Proteus spp. 17(10.2\%) (Table 2). And out of 61 anaerobic organisms, the most common isolates were Peptostreptococcus magnus $17(27.8 \%)$, followed by Bacteroides fragilis 15(24.5\%), Prevotella melaninogenica 12(19.6\%) (Table 3).

Monomicrobial flora was present in 42 (35\%) cases, of which aerobes were in $39(32.5 \%)$ cases and anaerobes were in $3(2.5 \%)$ cases. Polymicrobial flora were present in $78(65 \%)$ cases, of which 48 (40\%) cases were aerobic organisms and aerobic along with anaerobic organisms were isolated in $30(25 \%)$ cases.

The results of the test for susceptibility to the commonly used antibiotics are shown in Table 4. Almost all the strains of Pseudomonas aeruginosa was sensitive to imepenem (95\%), piparacillin/tazobactum $(87 \%)$ and least sensitive to ciprofloxacin (31\%), co-trimoxazole (26\%). Staphylococcus aureus were most often susceptible to vancomycin (100\%), clindamycin (84\%), Cefoxitin (66\%), but were relatively less susceptible to co-trimaxazole $(36 \%)$ and penicillin (33\%). Escherichia coli were 93\% sensitivity to imipenem, $90 \%$ to piparacillintazobactum while $36 \%$ and $30 \%$ resistance to cotrimoxozole and penicillin respectively. Klebsiella pneumoniae was found to be sensitive to Imipenem(100\%), piparacillin/ Tazobactum (85\%) and less sensitive to cotrimoxozole $(33 \%)$ and penicillin (28\%). Almost all the anaerobes were $100 \%$ sensitive to metronidazole. The antibiotic sensitivity pattern of anaerobic organism shown in Table 5 . 
Table.1 Showing patients' demographic data and clinical characteristics

\begin{tabular}{|c|c|c|}
\hline Sr.No. & Patient characteristics & Number \\
\hline a. & Male & $71(59.16 \%)$ \\
\hline \multirow{2}{*}{ b. } & Female & $49(40.84 \%)$ \\
\hline & Age wise distribution of patients & \\
\hline a. & $21-30 \mathrm{yr}$ & $3(2.5 \%)$ \\
\hline b. & $31-40 \mathrm{yr}$ & $7(5.83 \%)$ \\
\hline c. & $41-50 \mathrm{yr}$ & $24(20.0 \%)$ \\
\hline d. & $51-60 \mathrm{yr}$ & $41(34.17 \%)$ \\
\hline e. & $61-70 \mathrm{yr}$ & $27(22.5 \%)$ \\
\hline \multirow[t]{2}{*}{ f. } & $71-80 \mathrm{yr}$ & $18(15.0 \%)$ \\
\hline & Duration of diabetes mellitus & \\
\hline a. & Detected on Admission & $9(7.5 \%)$ \\
\hline b. & $1-5$ years & $33(27.5 \%)$ \\
\hline c. & $6-10$ years & $37(30.8 \%)$ \\
\hline d. & 11-15 years & $26(21.7 \%)$ \\
\hline \multirow[t]{2}{*}{ e. } & $16-20$ years & $15(12.5 \%)$ \\
\hline & Type of diabetes mellitus & \\
\hline a. & IDDM & $1(0.84 \%)$ \\
\hline \multirow[t]{5}{*}{ b. } & NIDDM & $119(99.16 \%)$ \\
\hline & Poor glycemic control (BSL>200 mg/dl) & $84(70 \%)$ \\
\hline & Smoking & $69(57.5 \%)$ \\
\hline & Hypertension & $58(48.4 \%)$ \\
\hline & Clinical findings associated with ulcer & \\
\hline a. & Fever & $68(56.6 \%)$ \\
\hline b. & Neuropathy & $61(50.8 \%)$ \\
\hline c. & Vasculopathy & $58(48.3 \%)$ \\
\hline d. & Crepitation & $45(37.5 \%)$ \\
\hline e. & Foul smell & $41(34.1 \%)$ \\
\hline f. & Cellulitis & $25(20.8 \%)$ \\
\hline g. & Osteomyelitis & $17(14.1 \%)$ \\
\hline \multirow[t]{2}{*}{ h. } & Gangrene & $8(6.6 \%)$ \\
\hline & Duration of diabetic foot ulcer in months & \\
\hline a. & $0-2$ & $19(15.84 \%)$ \\
\hline b. & $3-5$ & $37(30.83 \%)$ \\
\hline c. & $6-8$ & $41(34.16 \%)$ \\
\hline d. & $9-11$ & $18(15.0 \%)$ \\
\hline \multirow[t]{2}{*}{ e. } & $12-14$ & $5(4.17 \%)$ \\
\hline & Grading of lesions in the diabetic patients & \\
\hline a. & Grade -2 & $71(59.2 \%)$ \\
\hline b. & Grade-3 & $27(22.5 \%)$ \\
\hline c. & Grade-4 & $15(12.5 \%)$ \\
\hline d. & Grade-5 & $7(5.8 \%)$ \\
\hline
\end{tabular}


Table.2 Number and percentage of aerobic organisms isolated in the study

\begin{tabular}{|c|c|c|}
\hline Name of organism & $\begin{array}{c}\text { Number of } \\
\text { organisms }\end{array}$ & Percentage (\%) \\
\hline Pseudomonas aeruginosa & 41 & 24.70 \\
\hline Staphylococcus aureus & 33 & 19.88 \\
\hline Escherichia coli & 30 & 18.08 \\
\hline Klebsiella pneumonia & 21 & 12.65 \\
\hline Proteus mirabilis & 9 & 5.42 \\
\hline Proteus vulgaris & 8 & 4.82 \\
\hline Coagulase-negative Staphylococcus & 7 & 4.22 \\
\hline Streptococcus pyogenes & 5 & 3.01 \\
\hline Citrobacter freundii & 5 & 3.01 \\
\hline Enterococcus & 3 & 1.81 \\
\hline Enterobacter & 2 & 1.20 \\
\hline Acinetobacter & 2 & 1.20 \\
\hline Total & $\mathbf{1 6 6}$ & $\mathbf{1 0 0} \%$ \\
\hline
\end{tabular}

Table.3 Number and percentage of anaerobic organisms isolated in the study

\begin{tabular}{|c|c|c|}
\hline Name of organisms & $\begin{array}{c}\text { Number of } \\
\text { organisms }\end{array}$ & $\begin{array}{c}\text { Percentage } \\
(\mathbf{\%})\end{array}$ \\
\hline Peptostreptococcus magnus & 17 & 27.88 \\
\hline Bacteroides fragilis & 15 & 24.59 \\
\hline Prevotella melaninogenica & 12 & 19.67 \\
\hline Peptostreptococcus asaccharolyticus & 7 & 11.48 \\
\hline Fusobacterium & 5 & 8.19 \\
\hline Clostridium tetani & 3 & 4.92 \\
\hline Clostridium perfringens & 2 & 3.27 \\
\hline Total & $\mathbf{6 1}$ & $\mathbf{1 0 0} \%$ \\
\hline
\end{tabular}


Table.4 Showing antibiotic sensitivity pattern of aerobic organisms

\begin{tabular}{|c|c|c|c|c|c|c|c|c|c|c|c|c|c|c|c|c|c|c|c|c|c|c|c|c|}
\hline \multirow{2}{*}{$\begin{array}{c}\text { Name of } \\
\text { organism }\end{array}$} & \multicolumn{2}{|c|}{$\mathbf{P}$} & \multicolumn{2}{|c|}{ AMC } & \multicolumn{2}{|c|}{ CFX } & \multicolumn{2}{|c|}{ IMP } & \multicolumn{2}{|c|}{ PIT } & \multicolumn{2}{|c|}{ Va } & \multicolumn{2}{|c|}{$\mathbf{E}$} & \multicolumn{2}{|c|}{$\mathbf{G}$} & \multicolumn{2}{|c|}{ Cf } & \multicolumn{2}{|c|}{$\mathbf{C A Z}$} & \multicolumn{2}{|c|}{$\mathrm{CO}$} & \multicolumn{2}{|c|}{ CD } \\
\hline & No. & $\%$ & No. & $\%$ & No. & $\%$ & No. & $\%$ & No. & $\%$ & No. & $\%$ & No. & $\%$ & No. & $\%$ & No. & $\%$ & No. & $\%$ & No. & $\%$ & No. & $\%$ \\
\hline $\begin{array}{l}\text { Pseudomonas } \\
\operatorname{spp} .(n=41)\end{array}$ & - & - & 26 & 63 & - & - & 39 & 95 & 36 & 87 & - & - & - & - & 19 & 46 & 13 & 31 & 23 & 56 & 11 & 26 & - & - \\
\hline $\begin{array}{c}\text { S. aureus } \\
(n=33)\end{array}$ & 11 & 33 & - & - & 22 & 66 & - & - & - & - & 33 & 100 & 16 & 48 & - & - & 14 & 42 & - & - & 12 & 36 & 28 & 84 \\
\hline $\operatorname{E.coli}(n=30)$ & 9 & 30 & 12 & 40 & - & - & 28 & 93 & 27 & 90 & - & - & - & - & 14 & 46 & - & - & 15 & 50 & 11 & 36 & - & - \\
\hline $\begin{array}{c}\text { K.pnaemonae } \\
(n=21)\end{array}$ & 6 & 28 & 10 & 47 & - & - & 21 & 100 & 18 & 85 & - & - & - & - & 11 & 52 & - & - & 15 & 71 & 7 & 33 & - & - \\
\hline $\begin{array}{c}\text { P.mirabilis } \\
(n=9)\end{array}$ & 4 & 44 & 6 & 66 & - & - & 9 & 100 & 7 & 77 & - & - & - & - & 3 & 33 & - & - & 5 & 55 & 4 & 44 & - & - \\
\hline P.vulgaris $(n=8)$ & 3 & 37 & 6 & 75 & - & - & 8 & 100 & 7 & 87 & - & - & - & - & 5 & 62 & - & - & 4 & 50 & 3 & 37 & - & - \\
\hline CONS (n=7) & 3 & 42 & - & - & 5 & 71 & - & - & - & - & 7 & 100 & 5 & 71 & - & - & 4 & 57 & - & - & 3 & 42 & 6 & 85 \\
\hline $\begin{array}{c}\text { S.pyogenes } \\
(n=5)\end{array}$ & 3 & 60 & - & - & 4 & 80 & - & - & - & - & 5 & 100 & 4 & 80 & - & - & 3 & 60 & - & - & - & - & 4 & 80 \\
\hline C.freundii $(n=5)$ & 2 & 40 & 3 & 60 & - & - & 5 & 100 & 4 & 80 & - & - & - & - & 3 & 60 & - & - & 3 & 60 & 2 & 40 & - & - \\
\hline $\begin{array}{c}\text { Enterobacter } \\
(n=2)\end{array}$ & 1 & 50 & 1 & 50 & - & - & 2 & 100 & 2 & 100 & - & - & - & - & 1 & 50 & - & - & 2 & 100 & 1 & 50 & - & - \\
\hline $\begin{array}{c}\text { Enterococcus } \\
(n=3)\end{array}$ & 2 & 66 & - & - & - & - & - & - & - & - & 3 & 100 & 2 & 66 & 3 & 100 & 1 & 50 & - & - & - & - & - & - \\
\hline $\begin{array}{c}\text { Acinetobacter } \\
(n=2)\end{array}$ & - & - & 1 & 50 & - & - & 2 & 100 & 2 & 100 & - & - & - & - & 1 & 50 & 1 & 50 & 2 & 100 & 1 & 50 & - & - \\
\hline
\end{tabular}

E-Erythromycin, G-Gentamicin, Cf-Ciprofloxacin, CAZ- Ceftazidime, CO-Co-trimaxozole, CD- Clindamycin, P- Penicillin, AMC- Amoxacillin-clavulanate, CFX-Cefoxitin, IMP-Imipenem, PIT- Piparacillin/Tazobactam, Va-Vancomycin 
Table.5 Showing antibiotic sensitivity pattern of anaerobic organisms

\begin{tabular}{|c|c|c|c|c|c|c|c|c|c|c|c|c|c|c|c|c|}
\hline \multirow[t]{2}{*}{ Name Of Organism } & \multicolumn{2}{|c|}{$\mathbf{P}$} & \multicolumn{2}{|c|}{$\mathbf{N}$} & \multicolumn{2}{|c|}{ MT } & \multicolumn{2}{|c|}{ Va } & \multicolumn{2}{|c|}{ Cf } & \multicolumn{2}{|c|}{ CFX } & \multicolumn{2}{|c|}{$\mathbf{R}$} & \multicolumn{2}{|c|}{$\mathbf{K}$} \\
\hline & No. & $\%$ & No. & $\%$ & No. & $\%$ & No. & $\%$ & No. & $\%$ & No. & $\%$ & No. & $\%$ & No. & $\%$ \\
\hline $\begin{array}{c}\text { Peptostreptococcus } \\
\text { spp. }(\mathrm{n}=\mathbf{2 4})\end{array}$ & 23 & 95 & 16 & 66 & 24 & 100 & 24 & 100 & 10 & 41 & 17 & 70 & 12 & 50 & 18 & 75 \\
\hline $\begin{array}{c}\text { Bacteroides spp. } \\
(\mathrm{n}=15)\end{array}$ & 5 & 33 & 9 & 60 & 15 & 100 & - & - & 8 & 53 & 10 & 66 & 13 & 86 & 6 & 40 \\
\hline $\begin{array}{c}\text { Prevotella spp. } \\
(\mathrm{n}=12)\end{array}$ & 4 & 33 & 10 & 83 & 12 & 100 & - & - & 6 & 50 & 8 & 66 & 11 & 91 & 4 & 33 \\
\hline $\begin{array}{c}\text { Fusobacterium spp. } \\
(\mathrm{n}=5)\end{array}$ & 3 & 60 & 4 & 80 & 5 & 100 & - & - & 2 & 40 & 3 & 60 & 3 & 60 & 4 & 80 \\
\hline $\begin{array}{c}\text { Clostridium spp. } \\
(\mathbf{n}=5)\end{array}$ & 2 & 40 & 4 & 80 & 5 & 100 & - & - & 2 & 40 & 4 & 80 & 3 & 60 & 4 & 80 \\
\hline
\end{tabular}

P-Penicillin, N- Neomycin, MT-Metronidazole, Va- Vancomycin, Cf- Ciprofloxacin, CFX- Cefoxitin, R- Rifampicin, K-Kanamycin 
Diabetic foot is considered one of the most threatening and disabling complications for a diabetic patient as the lesions of the extremities can become so severe that the patient may risk the amputation of the toe, foot or leg ${ }^{7}$. Because of serious or recurrent infections and impaired healing processes, initially trivial lesion may progress to chronic non healing wounds, gangrene, or untreatable infections that can lead to limb amputation ${ }^{13}$.

In the present study, a total of 227 organisms were isolated from 120 patients, amongst that, $166(73.1 \%)$ were aerobes and $61(26.9 \%)$ were anaerobes. The present study, showed aerobic predominance which is in concurrence with various studies like Chincholikar et al., 7, Anandi et al., ${ }^{1}$, Gadepalli et al., 9, Banoo et al., ${ }^{3}$. Anaerobes were isolated less commonly in this study may be because of maximum number of patients had grade 2 or 3 lesion which are usually uncomplicated. As grading of lesion increases number of anaerobic organism increases because they are deep seated organism $^{8}$.

In the present study, Pseudomonas aeruginosa was the most commonly isolated organism and accounting for $24.7 \%$ of the total aerobic organisms. In the study of Bansal et al., , , Paul et al., ${ }^{16}$, Pappu et al., ${ }^{14}$ and Priyadarshini et al., ${ }^{11}$, reported that Pseudomonas aeruginosa was most common organism, accounting for $21 \%, 26 \%, 23 \%$ and $16 \%$ respectively. Our results are in near agreement with them. In contradiction, $S$. aureus is the most common organism in most of the studies like Chincholikar et al., 7 , Anandi et al., ' . While the prevalence of other aerobic organisms like Staphylococcus aureus, E. coli, Klebsiella pneumoniae was $19.8 \%, 18 \%$ and $12.6 \%$ respectively. Out of $61(26.9 \%)$ anaerobic organisms isolated, the most predominant anaerobic organism was Peptostreptococcus magnus (27.8\%), followed by Bacteroides sp. (24.5\%). Our results are in correlation with the studies of Vishwanathan et al., ${ }^{20}$ and Zubair et al., ${ }^{22}$, where they isolated Peptostreptococcus spp. as $36 \%$ and $35 \%$ correspondingly. In the present study, polymicrobial etiology was seen in $65 \%$ of the cases. Mixed aerobes were seen in $52.1 \%$ cases and aerobes along with anaerobes were seen in $16.6 \%$ cases this is in concordance with Chincholikar et al., 7 , Banoo et al., ${ }^{3}$, where polymicrobial etiology seen as $69.5 \%$ and $64 \%$ respectively.

With regards to antibiotic susceptibility pattern of aerobic isolates, all Gram-negative bacteria showed maximum sensitivity pattern to Imipenem (96.6\%), piparacillin/ tazobactam $(87.28 \%)$ and least sensitivity to co-trimoxazole (33.8\%), penicillin (32.4\%), ciprofloxacin $(31.8 \%)$. Similar findings seen in Banoo et al., ${ }^{3}$. While all Gram positive aerobic cocci $100 \%$ sensitive to vancomycin followed by clindamycin $(84.4 \%)$. MRSA was seen in $33.3 \%$ while Anandi et al., ${ }^{1}$ and Banoo et al., ${ }^{3}$ showed $20 \%$ and $66 \%$ MRSA pattern in their studies. In the present study, all the anaerobic isolated organisms were sensitive to metronidazole which is in correlation with Chincholikar et al., ${ }^{7}$, and Banoo et al., ${ }^{3}$.

In conclusion, diabetic foot ulcer is considered one of the most threatening and disabling complication for a diabetic patient. As diabetic foot infections are polymicrobial in nature. It should be recognized early and treated rigorously, then the incidence of amputation of limb will decrease drastically. The selection of the antibiotic treatment should be based on the predominant organisms which are isolated and their antimicrobial susceptibility patterns. This will improve the overall antibiotic utilization and reduce the emergence of multidrug resistant organisms. 


\section{References}

1) Anandi C, Alaguraja $D$, Natarajan V, Ramanathan M, Subramanian CS, Thulasiram M, et al., Bacteriology of diabetic foot lesions. Indian $\mathrm{J}$ Med Microbiol. 2004; 22(3):175-8.

2) Andersen CA, Roukis TS. The Diabetic Foot. Surg Clin N Am. 2007; 87:114977.

3) Banoo S, Shubha DS, Shashidhar V, Venkatesha D. Bacterial and clinical profile of diabetic foot patients. Ann Trop Med Public Health. 2012; 5: 6973. Page 117

4) Bansal E, Garg A, Bhatia S, Attri AK, Chander J. Spectrum of microbial flora in diabetic foot ulcers. Indian J Pathol Microbiol.2008; 51: 204-8.

5) Brown R, Collee JG, Poxton IR. Bacteroides, Fusobacterium and other Gram-negative anaerobic rods; anaerobic cocci; identification of anaerobes. In: Collee JG, Fraser AG, Marmion BP, Simmons A, editors. Mackei and McCartney. Practical Medical Microbiology.14 ${ }^{\text {th }}$ Edition. Churchill Livingstone: Elsevier publication; 2008: Pp. 501-11.

6) Culture Methods. In: Kapil A,Editor. Ananthnarayan and Panikars Textbook of Microbiology. 9th Edition. Hyderabad: Universities Press; 2009: p.45-8.

7) Chincholikar DA, Pal RB. Study of fungal and bacterial infections of the diabetic foot. Indian J Pathol Microbiol.2002; 45(1):15-22.

8) Edmonds ME. The Diabetic Foot: Pathophysiology and Treatment. Clin Endocrinol Metab. 1986; 15(4): 889916.

9) Gadepalli R, Dhawan B, Sreenivas V, Kapil A, Ammini AC, Chaudhry R. A. Clinico-microbiological Study of Diabetic Foot Ulcers in an Indian
Tertiary Care Hospital. Diabetes Care. 2006; 29(8): 1727-31.

10) Joseph WS, Axler DA. Microbiology and antimicrobial therapy of diabetes foot infections. Clin Podiatr Med Surg. 1990; 7: 467-81.

11) Laboratory Control of Antimicrobial Therapy. In: Kapil A, Editor. Ananthnarayan and Panikars Textbook of Microbiology. $\quad 9^{\text {th }} \quad$ Edition. Hyderabad: Universities Press; 2009: p. 635-9.

12) Lipsky BA, Berendt AR, Deery HG, Embil JM, Joseph WS, Karchmer AW et al., Diagnosis and treatment of diabetic foot infections. Clin Infect Dis. 2004; 39(7):885-910.

13) Monesi G, Manunta R, Perari D, Mollo F, Marchetto S, Chiarion L et al., The methodology and planning of an educational intervention in diabetic foot. Riv Inferm. 1991; 10(2):88-95.

14) Pappu AK, Sinha A, Johnson A. Microbiological profile of Diabetic Foot Ulcer. Calicut Medical Journal. 2011; 9(3): 1-4.

15) Pathare NA, Bal A, Tavalkar GV, Antani DU. Diabetic foot infections: A study of microorganisms associated with the different Wagner grades. Indian J Pathol Microbiol. 1998; 41(4): 437-41.

16) Paul S, Barai L, Jahan A, Haq A. A bacteriological study of diabetic foot infection in an urban tertiary care hospital of dhaka city. Ibrahim Med Coll J. 2009;3(2):50-4.

17) Rovan VU, Gubina M. Infection in superficial diabetic foot ulcers. Clin Infect Dis.1997;25(2):184-5.

18) Shanmugam $P$, Jeya $M$, and Linda SS. The Bacteriology of Diabetic Foot Ulcers, with a Special Reference to Multidrug Resistant Strains. J Clin Diagn Res. 2013; 7(3): 441-5.

19) Singh N, Armstrong DG, Lipsky BA. Preventing foot ulcers in patients with 
diabetes. JAMA. 2005; 293(2):217-28.

20) Viswanathan V, Jasmine JJ, Snehalatha C, Ramachandran A. Prevalence of pathogens in diabetic foot infection in South Indian type 2 diabetic patients. J Assoc Physicians India. 2002; 50: 10136.

21) Wild S, Roglic G. Green A, Sicree R,
King H. Global prevalence of diabetes. Diabetes care. 2004; 27(5):1047-53.

22) Zubair M, Malik A, Ahmad J. Clinicomicrobiological study and antimicrobial drug resistance profile of diabetic foot infections in North India. The Foot. 2011; 21: 6-14.

\section{How to cite this article:}

Prity Narwade and Nilekar, S.L. 2019. A Clinico-Bacteriological Study of Diabetic Foot Ulcers in a Tertiary Care Hospital. Int.J.Curr.Microbiol.App.Sci. 8(02): 750-759.

doi: https://doi.org/10.20546/ijcmas.2019.802.087 